\title{
A Framework to Promote Energy Efficiency as a Solution to the Energy Problem in Egypt
}

\author{
Sherin H. Sameh ${ }^{*}$, Basil Kamel ${ }^{2}$ \\ ${ }^{1}$ Dar Al Hekma University, Jeddsh, KSA \\ ${ }^{2}$ American University in Cairo, Cairo, Egypt \\ Email:*sherinsameh@yahoo.com
}

How to cite this paper: Sameh, S.H. and Kamel, B. (2017) A Framework to Promote Energy Efficiency as a Solution to the Energy Problem in Egypt. Energy and Power Engineering, 9, 187-215.

https://doi.org/10.4236/epe.2017.93014

Received: December 9, 2016

Accepted: March 28, 2017

Published: March 31, 2017

Copyright (c) 2017 by authors and ScientificResearch Publishing Inc. This work is licensed under the Creative Commons Attribution International License (CC BY 4.0).

http://creativecommons.org/licenses/by/4.0/

(c) (i) Open Access

\begin{abstract}
Egypt has been facing a vast power crisis in the past few years. A dilemma is projected to surge on the long run if not properly dealt with. The power sector is totally dependent on fuel, which is a primary source of energy in Egypt, and since the production of energy is not equivalent to the rising demand, so it becomes a major cause behind the power crisis. Efforts so far had been concentrating on the supply side, while neglecting an equally important part of the equation presumed by the demand side. On the other hand, energy efficiency is fast becoming an integral part of the demand, where the residential sector in Egypt plays a very important part with around $47 \%$ of power consumption, making it the highest sector consuming energy from the demand side, and hence presents a good opportunity to investigate in term of energy efficiency and the promotion of its applications in order to solve the energy problem, so that later the same concept can be applied in other sectors for a holistic solution to the both the power and the energy problem in Egypt. This study will focus on generating a political framework to promote energy efficiency as a solution to the energy problem in Egypt at end-user's level.
\end{abstract}

\section{Keywords}

Power Crisis, Energy Efficiency, End Users, Green Retrofitting, Residential Buildings

\section{Introduction}

\subsection{Overview}

Increasing energy efficiency is the quickest least expensive method for tackling energy crisis and the related economic challenges [1].

In Egypt the energy problem has resulted in a huge power crisis, and the nation has become in a desperate need to overcome this crisis in order to insure 
any political stability and economic growth. Egypt used to export oil and gas and now the country is facing a crisis in meeting its own demand. The increasing in energy consumption and collaterally the electricity consumption is merely a response to the country's development expansion and the people's life style. All the same increase in electricity consumption has increased the demands on the power sector which mainly relies on fuel, correlating to the national energy problem, which has also alternatively induced a huge financial burden on the government [2].

Hence there is an urgent need for the government to properly craft a comprehensive and innovative strategy that will help solve the power crisis/energy problem to guarantee economical, developmental and political stability on both the short term and the long one.

\subsection{The Electricity Problem in Egypt}

The equation for solving the electricity problem in Egypt should include the supply side, the demand side and energy efficiency techniques employed on both sides.

Most of the efforts taken so far have been concentrating on the supply side without really looking into the other half of the problem, which is induced by the end-users. There is no doubt that the shortage in the supply of energy represents a big part of the problem, however as long as there is a general neglect to the role of end-users in the problem, the proposed solution will continue to be temporary.

This is due to the simple logic that with the on-going growing population, and the expanding development needs, there will continue to be a constant increase in the energy demand. So that whatever the resources that are proposed to deal with the current supply shortage, there will be an increasing struggle to surpass the demand in the future. Therefore, a supply/demand strategy will properly formulate a solution for the energy problem and will provide an adequate balance that is projected to be more sustainable on the long run.

On the other hand, it is also important to point out that any proposed strategy should also include increasing the energy efficiency in each of the demand and supply side, a solution which represents a cost-effective technical and financial alternative to moderate the energy demand growth and thus make sure to keep the energy balance carefully thought of for the long run [3].

This brings to focus on the power crisis facing Egypt nowadays, where a huge opportunity to promote energy efficiency as a national policies. Also it is safe to say that energy efficiency will not be properly applied in case it is left to neither the industry nor the household users, as these sectors are not well informed and their impact on the problem will be minor and not effective if they are not sheltered under the umbrella of an adequate environmental policy. Hence there is a major role for the government in term of intervention to provide an environmental policy that can adequately solve the energy problems in Egypt by promoting energy efficiency and not only depending on allocating resources to in- 
crease the supply side. However, in order to properly assess the current problem, first it is important to reflect on the current electricity and power sector's status.

\subsubsection{Electricity Production in Egypt}

In Egypt the responsibility of the power sector is delegated to two different ministries. The first one is the Ministry of Petroleum, and its job entitles the management of the upstream and downstream oil and gas activities. The other one is the Ministry of Electricity and Energy which manages the electricity generation, transmission and distribution. This can be illustrated in Figure 1.

The Egyptian Electricity Holding Company (EEHC) has increased the Peak load from 19,738 MW to 25,705 MW from the tear 2008 to the year 2012. EEHC has also reduced the power losses from $11.27 \%$ to $10.79 \%$. These efforts however were obviously not enough to fill the gap or to solve the power problem [4].

The power production in Egypt is mainly generated from;

- Hydro Power

- Thermal Power

- Private sector

- Purchased Power from Industrial Plants

- Isolated Power Plants

The Table 1 illustrates an overlook on the electricity production for the year 2011/2012.

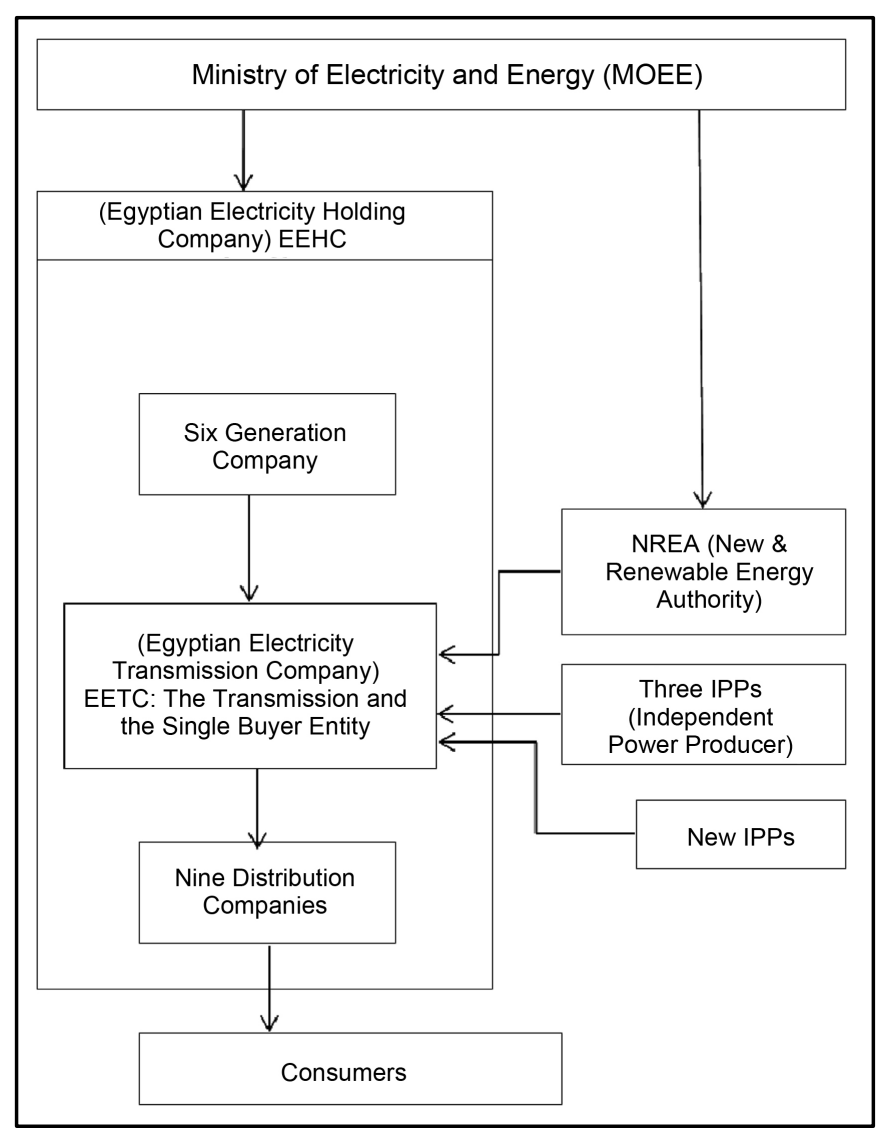

Figure 1. Structure of power section [2]. 
Table 1. Electricity in Egypt 2011, 2012 [5].

\begin{tabular}{|c|c|c|c|c|}
\hline \multicolumn{2}{|l|}{ Description } & $2010-2011$ & 2011-2012 & Variances \\
\hline Peak load & MW & 23,470 & 25,705 & 9.5 \\
\hline Total energy generated & GWH & 146,796 & 157,406 & 7.2 \\
\hline Hydro & GWH & 13,046 & 12,934 & 0.9 \\
\hline Thermal & GWH & 118,500 & 129,361 & 9.2 \\
\hline Renewable & GWH & 1704.4 & 2004 & 17.6 \\
\hline Energy purchased from IPP'S & GWH & 27.3 & 29 & 6.2 \\
\hline Private sector (boots) & GWH & 13,309 & 12,855 & 3.4 \\
\hline Isolated plants & GWH & 209 & 223 & 6.7 \\
\hline $\begin{array}{l}\text { Net energy exchange with } \\
\text { interconnected countries }\end{array}$ & GWH & 1443 & 1576 & 9.2 \\
\hline $\begin{array}{l}\text { Set energy from production } \\
\text { companies (without boot) }\end{array}$ & GWH & 127,427 & 137,891 & 8.2 \\
\hline Total fuel consumption & $\mathrm{K}$ toe & 27,430 & 29,728 & 8.4 \\
\hline Production companies & $\mathrm{K}$ toe & 24,698 & 27,083 & 9.7 \\
\hline H. F. O & $\mathrm{K}$ toe & 5204 & 4560 & 124 \\
\hline N. G & $\mathrm{K}$ toe & 19,404 & 22,458 & 15.7 \\
\hline L.F.O & $\mathrm{K}$ toe & 90 & 65 & 27.8 \\
\hline Private sector boots & $\mathrm{K}$ toe & 2732 & 2645 & 3.2 \\
\hline $\begin{array}{l}\text { Thermal efficiency without pri- } \\
\text { vate sector (boots) \% }\end{array}$ & & 42.1 & 41.9 & 0.5 \\
\hline N.G ratio to fuel including boots & $\%$ & 80.4 & 84.3 & 4.9 \\
\hline $\begin{array}{l}\text { N.G ration for power plants } \\
\text { connected to gas grid including } \\
\text { boots }\end{array}$ & $\%$ & 83.8 & 86.5 & 3.2 \\
\hline Total installed capacity & MW & 27,049 & 29,074 & 7.5 \\
\hline Hydro & MW & 2800 & 2800 & - \\
\hline Thermal & MW & 21,514 & 23,539 & 9.4 \\
\hline Renewable & MW & 687 & 687 & - \\
\hline Private sector boots (thermal) & MW & 2048 & 2048 & - \\
\hline $\begin{array}{c}\text { Total length on transmission } \\
\text { lines \& cables }\end{array}$ & $\mathrm{km}$ & 42,223 & 43,634 & 3.3 \\
\hline $\begin{array}{c}\text { Total power of transformers } \\
\text { capacity }\end{array}$ & MVA & 87,400 & 91,865 & 501 \\
\hline $\begin{array}{c}\text { Total length of distribution MV } \\
\text { \& LV lines \& cables }\end{array}$ & KM & 39,429 & 405,199 & 2 \\
\hline $\begin{array}{l}\text { Total length of distribution } \\
\text { transformers MV \& LV }\end{array}$ & MVA & 57,925 & 59,958 & 3.5 \\
\hline $\begin{array}{l}\text { Total number of customers in } \\
\text { distribution companies }\end{array}$ & Millions & 26.6 & 28.1 & 5.6 \\
\hline
\end{tabular}


The capacity by type of Generation is in the illustrated Figure 2.

From the previous information it is clearly obvious that renewable energy is not properly utilized in the EEHC's Plan. It is obvious from in Figure 3 that the renewable energy sources considered is; wind and sun energy, and even in comparison the sun is poorly utilized.

In a country like Egypt which is sunny all year, solar energy generation should be better developed as a clean energy alternative. Especially that around different countries in the world it has successfully become a viable energy source in many governmental development plan.

It is also important to highlight that the government has already started initiating different projects that is aiming to help with the power shortage from the supply side. One of these obvious efforts is a result of the economic conference that took place in Egypt, at Sharm El Shiek this March. Where the focus was directed towards introducing some renewable energy sources that can help make energy generation more sustainable. So for example it was reported that; 'General Electric Co.'s Schenectady-based Power \& Water unit has landed a \$1.7 billion deal with Egypt to provide that country with 43 turbines to add nearly 2.7
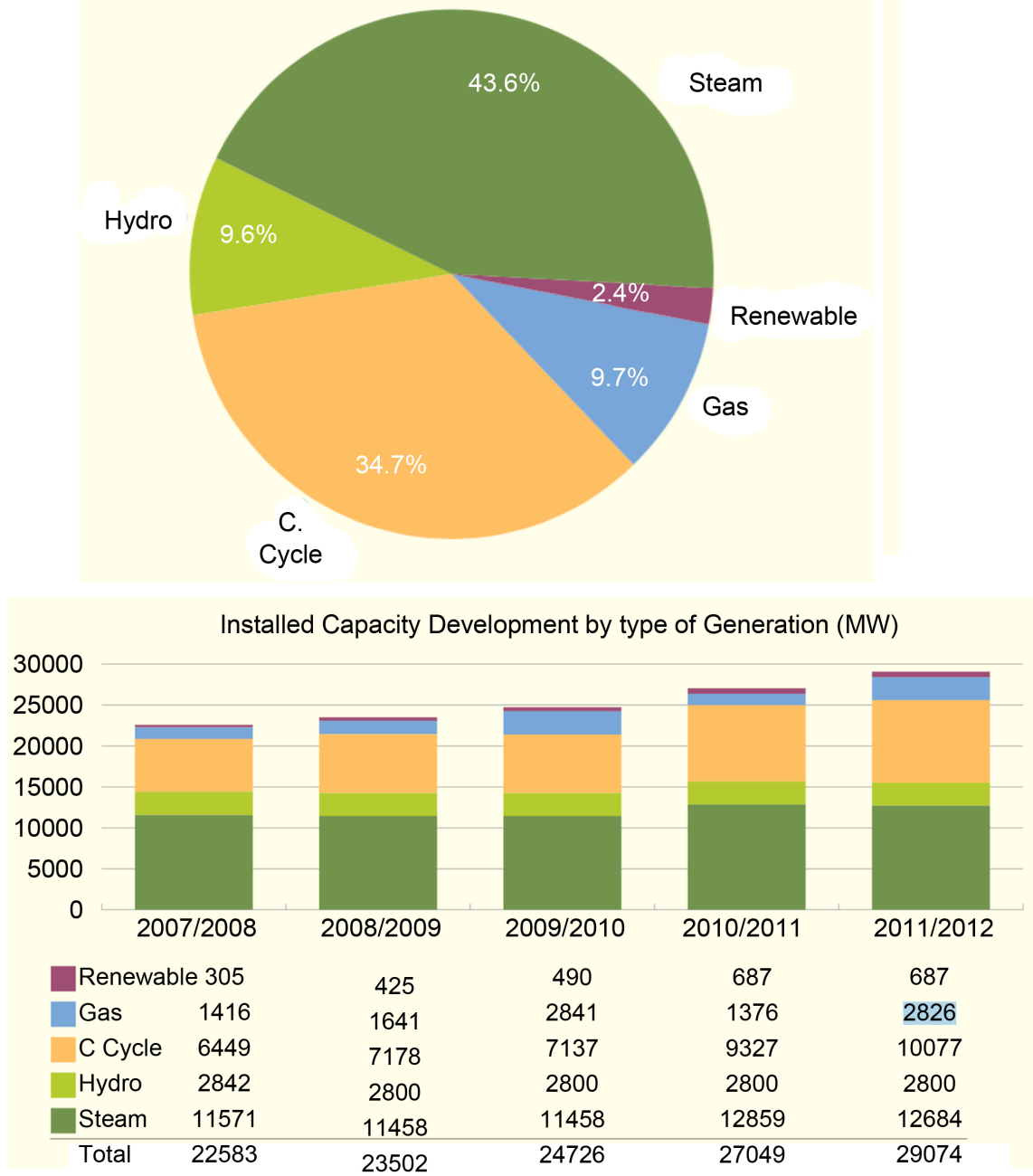

Figure 2. Installed capacity by type $\left(\mathrm{MW}^{\star}\right)$. 


\begin{tabular}{|c|c|c|c|c|}
\hline \multicolumn{2}{|c|}{ Type } & $2010 / 2011$ & $2011 / 2012$ & Variance \% \\
\hline Steam & $\begin{array}{c}\text { Affiliated } \\
\text { Companies }\end{array}$ & 56502 & 57718 & 2.2 \\
\hline Private Sector & 13309 & 12855 & $(3.4)$ \\
\hline Gas Turbine & 3795 & 10238 & 169.8 \\
\hline Comb. Cycle & 58203 & 61405 & 5.5 \\
\hline Total Thermal & 131809 & 142216 & 7.9 \\
\hline Hydro & 13046 & 12934 & $(0.9)$ \\
\hline Renewable & 1485 & 1525 & 2.7 \\
\hline Solar/Thermal & 219.4 & 479 & 118.3 \\
\hline Total Grid & 146559 & 157154 & 7.2 \\
\hline Isolated Plants & 209 & 223 & 6.7 \\
\hline Purchased from (IPP's) & 27.3 & 29 & 6.2 \\
\hline Grand Total & 146796 & 157406 & 7.2 \\
\hline
\end{tabular}

* The energy generated includes commissioning tests * Unit used is $\left(\mathrm{MW}^{*}\right)$

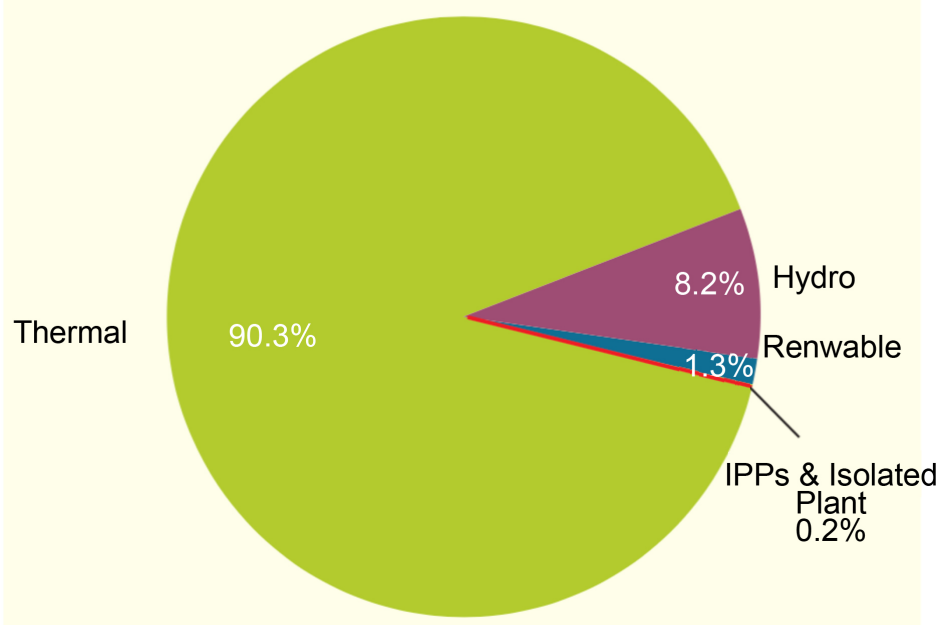

Figure 3. Energy generated and purchased by type and technology [5].

gigawatts of power to its electrical grid-enough for 2.5 million homes' [6]. This example is one of the different efforts that have been taken to cut the electricity shortage from the supply side, yet again it might not be enough if the demand is not stabilized on the long run.

\subsubsection{Electricity Consumption in Egypt}

In Egypt, the majority of the population and the hence customers of the EEHC lies in big cities especially in the capital. Cairo has become the main location for electricity consumers of the power sector. In fact, Cairo's customers have become so high in number, that they had to be divided to south Cairo and north Cairo and both part are highly competing with other big cities. This is clearly illustrated in Figure 4. 


\begin{tabular}{|l|c|}
\hline COMPANY & NO. OF CUSTOMERS \\
\hline North Cairo & $3,761,517$ \\
\hline South Cairo & $4,704,639$ \\
Alexandria & $2,211,766$ \\
Canal & $3,176,847$ \\
North Delta & $3,301,659$ \\
South Delta & $3,638,077$ \\
\hline El Behera & $1,807,231$ \\
Middle Egypt & $3,037,717$ \\
Upper Egypt & $2,429,477$ \\
\hline 5000000 & \\
\hline
\end{tabular}

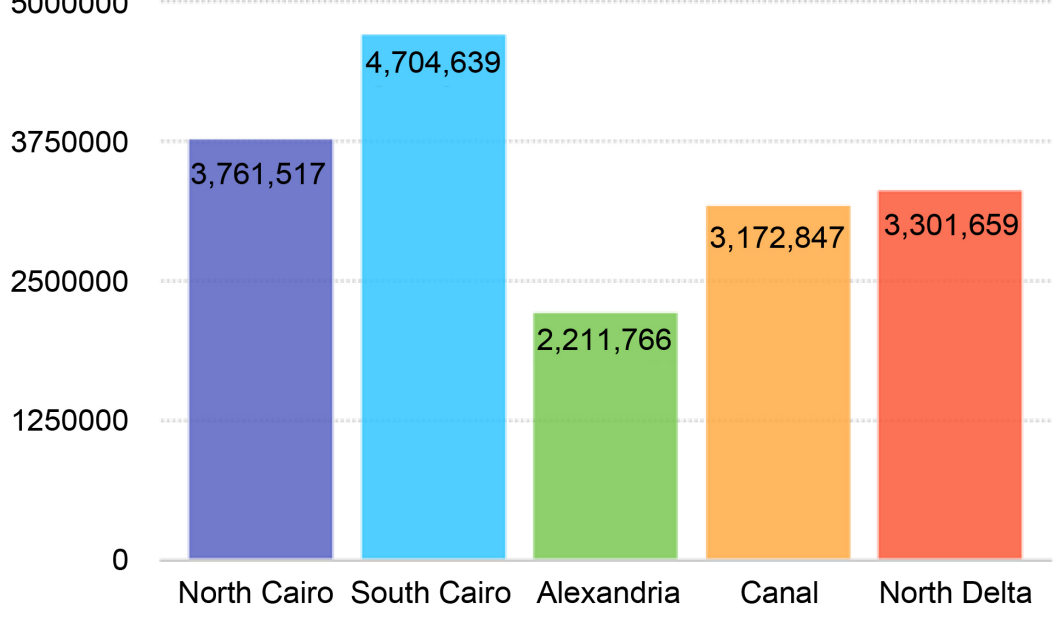

Figure 4. Number of customers in distribution companies [5].

The main focus of the research is considering the electricity problem from the demand side at the residential level, and Figure 5, illustrate and further proof the huge role that the residential sector play in term of usage according to the EEHC 2012 report, which is estimated to be up to $70 \%$ from the total use.

\subsection{Energy Efficiency in Egypt}

In the international community many countries have pursued and effectively fostered energy efficiency policies and in result were rewarded with a noticeable decrease in their energy intensity. On the other hand, Egypt, a country whose economy is based on the intense use of energy has only induced a few improvements due to its lacking environmental policy [3]. In this regard there is a strong need for Egypt to start focusing more organized efforts on its environmental policy and to properly push for energy efficiency promotion in all sectors.

Looking into international energy efficiency practices for guidance it is noted that the 2011 IEA report has set seven priority areas that can help its member countries to achieve the benefits of energy efficiency across their economies [1]. The considered priorities were as following: 


\begin{tabular}{|l|c|}
\hline \multicolumn{1}{|c|}{$\begin{array}{c}\text { Purpose of } \\
\text { Usage }\end{array}$} & No. of Customers \\
\hline Industry & 572839 \\
\hline Agriculture & 73260 \\
\hline Gov.\& Public Utilities & 200615 \\
\hline Residential & 19823502 \\
\hline Commercial & 1369251 \\
\hline Closed and postponed & 3235494 \\
\hline Other & 512845 \\
\hline Zero reading & 2277124 \\
\hline \multicolumn{1}{|c|}{ Total } & 28064930 \\
\hline
\end{tabular}

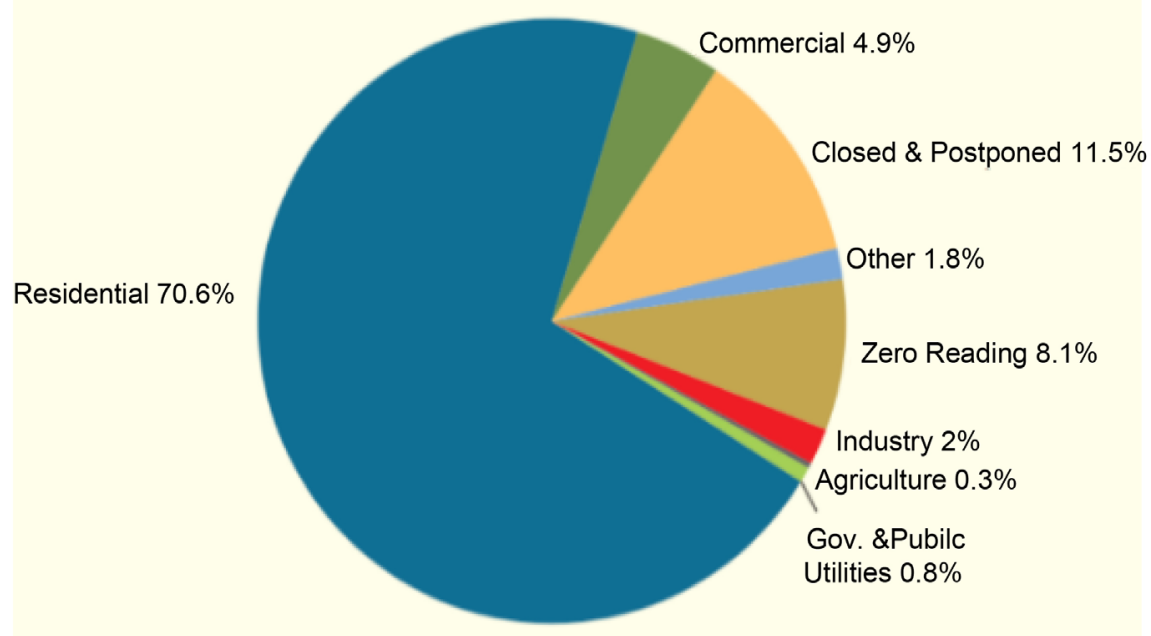

Figure 5. Number of costumers according to purpose of use [5].

- Buildings

- Appliances and equipment

- Lightning

- Transport

- Industry

- Energy utilities

It was then estimated that if proper action was taken in term of policies it could result in savings of 7.6 giga-tonnes $(\mathrm{Gt}) \mathrm{CO}_{2}$ /year worldwide by the year 2030, as seen in Figure 6.

It was mentioned earlier in the research the role that the residential sector play in term of energy use in Egypt, a main reason for selecting it as the sector to try to tackle to promote energy efficiency through a properly structured policy that can be later adapted and used for intervention in other sectors as well. Hence out of the seven IEA report priorities the research will be looking into the first four, as in this case they are the one related to the residential sector. 


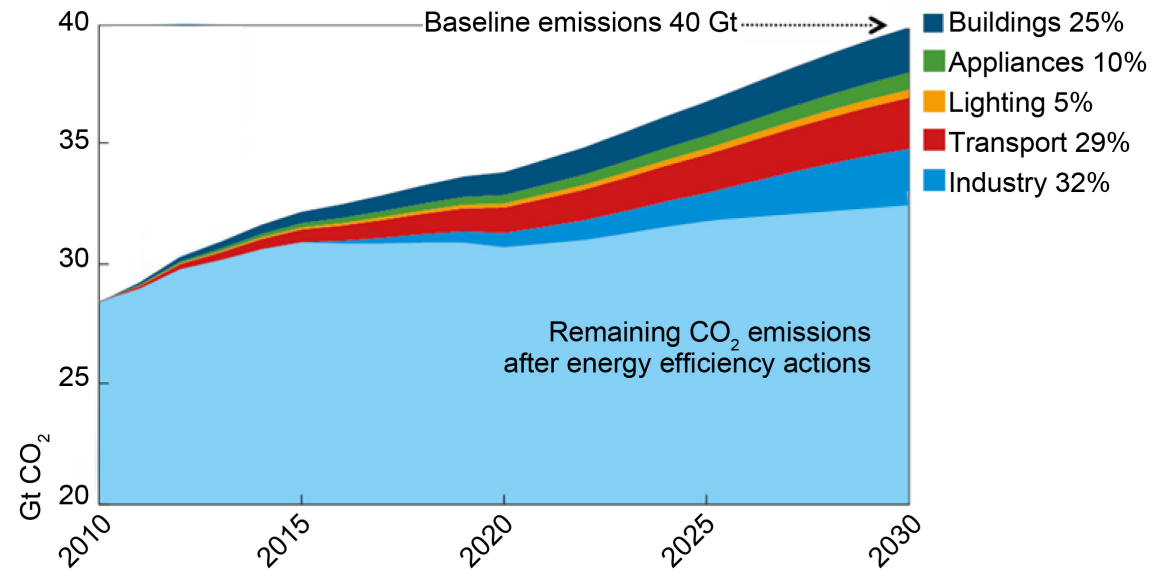

Figure 6. $\mathrm{CO}_{2}$ savings potential from energy efficiency recommendations [1].

\subsubsection{Indirect Benefits of Energy Efficiency}

It is also important to highlight that beside the many economic and political benefits for energy efficiency, there are other social indirect benefits to increasing the energy efficiency in the residential and commercial sector. Some of these indirect benefits are; reducing the food spoilage, extending clothing life, and other similar factors [7]. The three following sets highlight the main indirect benefits and are as following:

Impact on Comfort and Health: as people spends $90 \%$ of their time indoors [7]. Enhancing the indoor air quality and indoor climatic comfort is part of the indirect benefits that comes from applying different energy efficiency techniques. These techniques will be touched upon further into the research with more details.

Impact on Productivity: a study by Lawrence Berkley National Laboratory suggests that enhanced indoor air quality directly affects the productivity of the occupants of the building [8].

Impact on poverty Alleviation: energy efficiency can help reduce house-hold bills and on-going expenses, which will directly impact the status of the low-income households [7].

\subsubsection{Previous Energy Efficiency Initiatives in Egypt}

Since the 1980s many initiatives were taken in term of energy efficiency improvement, yet their impact is still weak and their results are inadequate or limited [9]. Those initiatives and their key issues are summarised in the following:

- The Energy Efficiency Improvement and Greenhouse Gas Reduction Project, this project was hosted by the EEHC and the MOEE and financed by a grant from the United Nations Development Program (UNDP). This project started in 1999 and its original plan was to finish by 2003 however it was extended many times and stopped in June 2010. In the end it was evaluated in term of its outcomes and although it covered some of the mile stones required however it was never completed and the programs it launched were not properly implemented [10]. An example of this is the CFLs promotion 
program which was launched in order to promote the use of CFLs instead of regular incandescent lamps as a more sustainable option. However, the project's promotion was not properly induced and needs better monitoring to reflect the desired impact.

- The USAID and the UNDP has supported the government in creating a few Energy Service companies (ESCO Business), however the few of them remaining are facing many financial problems [3].

- A Number of energy audits were carried out, but very few of them were followed through [2].

- The Organization of Energy Planning (OEP) was previously launched to promote energy efficiency; however, it ceased function in 2005. Also the energy efficiency standards for four domestic appliances and energy efficiency building codes for new facilities were developed under the UNDP/EEIGGR project but compliance with those standards and codes are still voluntary, are not properly implemented [3].

\subsection{Cross-Sectorial \& Building's Policy Making Review}

In the past decade concerns over energy security has been the focus of many governments, in particular in countries that rely increasingly on imports to meet their growing domestic energy demand [11]. This case is apparent in Egypt, where the power crisis has been a major national problem in the past few years hindering its economic development, and played an important role in triggering its political instability as well.

The solutions for these problems are usually offered by the government due to the required authority to make required changes. Policy making is a very crucial tool in this agenda. The logical approach to this problem should be a top-down change. Usually top-down change is the one considered when the problem has a strategically and high impact status [12], which is the case in this matter. However, top-down change strategies should not be linear and it should include other stake holders in order to guarantee commitment and effective results.

It is also important to note that in developed countries nowadays the problem with sustainability applications in the building sector is not the lack of guidelines, rules or regulations. The real problem lies in the application of these rules and currying them through to the endeavours level.

"Nearly all jurisdictions struggle to implement environmental regulations. In a 2012 survey of both developed and developing countries, national auditing offices were asked to identify the greatest obstacle ministries face in environmental protection. They responded unequivocally: the single greatest challenge is implementing laws and regulations already on the books" [13].

The government in this case should be the pushing engine across the different sectors with the right policy and regulations.

For governments to demonstrate tangible environmental impact for their produced policies more focus should be on; regulatory implementation, measuring the impact, providing transparency, and considering accountability, in 
order to ensure the delivery of the benefits implemented in these policies [14]. There is a general fatigue of generating laws and regulations that are not carried through.

The domestic level in specific plays a very important rule in this agenda, and the general lack of awareness, ignorance and the dwindling public interest in these applications, are a main reason and a challenge that faces any step forward. This is why the research is focused on the domestic level, being the biggest consumers of energy in Egypt and as part of tackling the problem at its highest demand.

\subsection{Strategies for Energy Efficiency at End-Users Level}

Researchers have identified three different measures for promoting energy conservation at end users level [7] [15].

The first type is the behavioural measures which usually impact the knowledge, perception, motivations, and norms of energy conservation. Such measures usually lead to a behavioural change scenario where users become actively involved, which result in tangible energy conversation. Other researchers [16], have identified these measures as a communicative instrument, that the government can use in order to implement an energy efficiency policy. Behavioural measures usually include awareness campaigns, education, and other similar tools. Yet by definition these instruments should be non-commercial in nature, and should be aiming to highlight the public benefits resulting from their applications.

Another study by Janet Thomson [17], supports the same theory, by indicating that change is usually influenced by one of three different factors; a novel situation, shock, or intense focus. In case of intense focus this can be applied by using repetitiveness and awareness to promote this change. So awareness becomes a very important factor in promoting energy efficiency and pushes it at end users level.

The second type is known as the structural strategies, which are designed to target the decision making context in term of; incentives and regulatory instruments that can assure that energy conservation is well considered and implemented.

The Third type is the availability of resources or the economic instruments that can help supporting any suggested plan and properly implement it. This measure has been the main struggle in Egypt due to the current political status, which is affecting the economic stability. Yet again the economic instruments have been also the only focus for the Egyptian government for the past few years when dealing with the energy crisis, where other measures were neglected or mildly considered.

However, it is important to point out that the three mentioned above strategies are of equal importance and ignoring one of them will not properly tackle the energy problem, and so if one of them is ignored, the offered solutions will be lacking and it will not formulate a holistic approach. 


\subsection{Challenges and Barriers Identified}

Energy efficiency has become a common goal for many countries worldwide. At this stage the requirement is questioning how you can produce more using less energy [7]. However, despite the different studies aimed to tackle energy efficiency, yet there remain a few unresolved issues that are hindering its applications and exposing its full potential. These issues will be discussed in this part, both internationally, and nationally by focusing on the Egyptian case.

\subsubsection{General Challenges}

Energy efficiency has some common challenges that are hindering its application and its progress. Some of these challenges are discussed in the following:

- One of these major challenges is the assumption that it would require a considerable upfront investment in return for the promised savings that are usually assumed to be returned only on the long run. On the other hand, this assumption is case sensitive and it cannot be generalised, as more probably in most cases energy efficiency is considered an easy quick way to save costs.

- Financing remains as one of the major challenges that face the promotion of energy efficiency worldwide, as it has always been a hard sell because electricity is invisible [18].

- Energy efficiency is considered intangible, and it is usually scattered across many locations, different users and devices, and across different sectors [7]. This in return makes it hard to track, and it makes its responsibility abided by no one, which is very obvious in the Egyptian case. To find the solution for the barriers of energy efficiency it then becomes more important to have a holistic overreaching strategy that is headed by an influential entity, which in this case should be represented by the government.

\subsubsection{Case Specific Challenges}

In this part of the research and in order to properly formulate the required framework it is important to identify the barriers and challenges that could face energy efficiency as a cross-sectorial policy in general and the building's sector policy in specific with regards to Egypt, which are summarized in the Table 2, and they have been divided into the three different measures, which were discussed above: behavioural, structural and availability of resources.

\subsection{Proposed Actions}

Many developed countries that were successful in promoting and harvesting the required results of energy efficiency has used a mix of governmental laws and regulations, along with policies and special programs that are designed to raise the awareness and encourage investors to look into energy efficiency applications[3]. Also by looking into related studies to the proposed topic [15], the following three actions were deduced as an appropriate base to the required framework to promote energy efficiency along the residential demand side:

- Awareness:

This action is concerned with end-users in general, in order to highlight to 
Table 2. Barriers and challenges facing energy efficiency promotion in Egypt.

\begin{tabular}{|c|c|c|}
\hline & $\begin{array}{c}\text { Cross-Sectorial Barriers and } \\
\text { Challenges }\end{array}$ & $\begin{array}{c}\text { Building sector's Barriers and } \\
\text { Challenges }\end{array}$ \\
\hline & $\begin{array}{l}\text { - General lack of awareness by the end-users } \\
\text { on their impact on the energy crisis, and the } \\
\text { excess use of energy that they consume. } \\
\text { - No incentives for investors to invest in } \\
\text { energy efficiency application. }\end{array}$ & $\begin{array}{l}\text { - General lack of awareness of the } \\
\text { end-users and construction } \\
\text { practitioners. } \\
\text { - No familiarity with energy } \\
\text { efficiency products. } \\
\text { - No incentives for end-users to } \\
\text { accommodate energy efficiency } \\
\text { applications. } \\
\text { - Lack of interest in energy } \\
\text { efficiency applications. }\end{array}$ \\
\hline 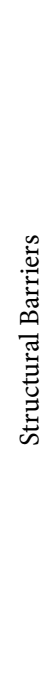 & $\begin{array}{l}\text { - Lack of effective actions by the } \\
\text { government to address energy } \\
\text { efficiency in all sectors [3]. } \\
\text { - The absence of an effective policy. } \\
\text { - Lack of transparency and information on } \\
\text { the required methods and tools that can } \\
\text { achieve energy Efficiency. } \\
\text { - There is no institutional framework to } \\
\text { promote energy efficiency and there are no } \\
\text { dedicated prohibitive laws or regulations } \\
\text { that call for the implementation of energy } \\
\text { efficiency [2]. } \\
\text { - Conflicting authorities and the absence of a } \\
\text { regulating body that can help in } \\
\text { implementing and following up on the } \\
\text { applied energy efficiency methods. } \\
\text { - The lack of clarity for energy efficiency } \\
\text { schemes and the high risk associated. }\end{array}$ & $\begin{array}{l}\text { - The residential energy efficiency } \\
\text { code is not properly implemented } \\
\text { [9]. } \\
\text { - Energy saving is a hard sell as it is } \\
\text { non-tangible, especially when it } \\
\text { involves different buildings, } \\
\text { applications and large } \\
\text { number of users. } \\
\text { - Efficiency tools are fragmented } \\
\text { across the residential sector and it is } \\
\text { hard to account its data or keep } \\
\text { track of it. }\end{array}$ \\
\hline & $\begin{array}{l}\text { - The lack of technical capacities [3]. } \\
\text { - The technology used in Energy efficiency } \\
\text { is not well recognized and is usually } \\
\text { expensive. } \\
\text { - A lack of a specific fund } \\
\text { dedicated for energy efficiency promotion } \\
\text { and implementation strategies. } \\
\text { - The absence of an adequate policy for } \\
\text { promoting energy efficiency. } \\
\text { - Absence of utilities as executing } \\
\text { agencies [3]. } \\
\text { - Lack of Governmental incentives and } \\
\text { motivational schemes that encourage the } \\
\text { private sector to invest in energy efficiency } \\
\text { schemes. } \\
\text { - The assumption of high initial cost } \\
\text { impaired with energy efficiency tools and } \\
\text { applications, without realising the promising } \\
\text { saving it represent on the long run. }\end{array}$ & $\begin{array}{l}\text { - No familiarity with the different } \\
\text { technologies available nor the } \\
\text { savings that they offer. } \\
\text { - Substantial initial cost is required } \\
\text { to invest in energy efficiency } \\
\text { applications. } \\
\text { - People shy away from } \\
\text { accommodating energy efficiency } \\
\text { applications due to the assumed } \\
\text { higher initial cost without } \\
\text { properly also considering the } \\
\text { saving it will apply on the long run. }\end{array}$ \\
\hline
\end{tabular}

them the impact of their energy use, and make them understand as well as direct them towards the possible logical ways that can help to regulate and decrease their consumption, while understanding the benefits that such act will reflect. Yet again to guarantee the required change taking place, usually awareness 
should be associated by highlighting the gains rather than indicating the losses so that users are motivated to carry it through [17], which take us to the following next factor.

- Motivation:

Different stakeholders should become motivated to consider energy efficiency and its applications, as part of an urgent requirement to solve electricity and all related energy problems on the long run.

- Compliance:

Generated rules and regulation is very important to insure the implementation of the required goals for energy efficiency and guarantee their following through to insure the continuous impact required.

\subsection{Case Studies and Best Practice Examples}

In order to find solutions to the barriers and challenges facing the applications of energy efficiency in buildings and across policy making in Egypt, it is important to take into account the experience and best practice examples that have been successful on other countries, or by other international organizations. So in this part of the research, the focus will be on analysing some case studies in order to develop a few guidelines that can help solve the energy problem based on lessons learned from other successful experiences.

\subsubsection{Awareness}

In Egypt in the recent few years, people became very much aware of the rising energy problem, and this is as mentioned before, due to the clear evidence and the consequences that they have endured in their everyday life, as a result of the current energy crisis. However, the perceptions still focus on the supply side as the actual trigger of this dilemma, and although this is partly true, however it is neither the only nor the most effective solution. The awareness of the people towards their role in the problem is a significant element in order to find proper solutions. Lots of educated people are aware that global warming is due to the ozone depletion, however very few of them understand that the major contributor in global warming is due to exhaust resulting from heating and cooling homes [19].

In general people are not actually aware of the energy use related to their behaviour [15]. In some cases, people tend to believe that the amounts of energy they use depend on the size of the appliance, so the larger the equipment the more energy it uses [20], however this heuristic is not always true.

Overall for energy conservation to work at the end users level, people awareness and knowledge should be increased and there should be an emphasis on a behavioural change plan that can help increase the awareness, and give those alternatives on how to decrease the consumption and increase efficiency from the end-user's side. Behavioural change is a very important factor to achieve the required awareness. Social marketing theories argue that people will welcome a required change and adopt new behaviour if two conditions are met: 1) the person must understand the required, and believe he/she is capable and knowl- 
edgeable to take the action, 2) a person must believe that the circumstances around him will permit the behaviour and allow positive outcome [21]. Hence there is a need to structure a public campaign that will help deliver the knowledge required, and persuade the users that they can take these actions in order to save energy and achieve the required outcome.

Many countries have been very successful in acquiring the general attention using awareness campaigns and incentives schemes. These campaigns are usually referred to as Public information campaigns (PICs). PICs are defined as methods designed by the government to encourage individuals to change their behaviour, attitude, value or knowledge [22].

PICs fit in the social marketing schemes. For decades' governments have used similar schemes widely in the health area [23]. This was apparent in Aids prevention, smoking and the famous Bilharzia campaign that took place in Egypt between the late 800 s and early 90s. However, in the last two decades the same method was used in many developed countries to promote sustainability applications like for example; recycling.

Usually the PICs are categorized as policy instruments that usually have symbolic value to the governments [22].

In most cases PICs can be very tricky because once the target audience has seen a campaign and understood its message, they might act upon it or not. So in order to effectively influence the audience believe and persuade them to act upon it, the message intended must provide new information, trigger norms and direct attention [22].

Through the illustration of the following case studies of PICs, the effectiveness of them as an important tool will be highlighted, in order to consider the different lessons that could be learned and applied within the Egyptian context:

1) Case Study 1

In 1997 the government of Lithuania faced a vile situation regarding the country's energy consumption. From this situation emerged an idea to raise awareness of energy savings in the residential sector [24]. The main idea was to set up a five-year strategy to implement energy efficiency across the residential sector through a media campaign, and they called the aimed campaign "Taupukas" (which means "saver" in English).

The "Taupukas" program started on 1998 and was completed on 1999. The government assigned the program to the Energy Efficiency Centre of the energy agency. A budget of 400,000 EUR was set for the project and was to be provided by the Phare program.

The Energy Efficiency Centre and they partnered with a public relations firm called; Kredo R, advertising and a media firm called; AGE Reklama and a market research firm called; Gallup Baltic Survey.

The goals of the campaign was to increase energy efficiency at the residential sector, raise awareness of end users towards their energy consumption and illustrate benefits of energy savings to the public.

The campaign has focused on media tools like the radio and television for 
promotion. Interviews, seminars were also part of the set campaign and the "Taupukas" brand image was shown in all related events, which made it quite popular and well identified by the audience.

The campaign also involved some simple advices that the users can follow to decrease their energy consumption and related bills.

Two survey research studies took place during the project. The first survey took place in the beginning to identify the target groups, message and media. The second was carried a year later to change the success of the implemented campaign and the overall change it presumed.

The results of the program were overall positive. It captured the interest of the public and it was cost effective for the users, presenting them with free information about how to save on their energy, which also included financial savings. However, it was noted that marketing campaign should be a long term one, so that the message it delivers will continue. Also the Energy Efficiency Centre needed to interact more with similar institutions to form an information networks that can maintain the knowledge and pass it on.

\section{Lessons learned:}

For any government to implement a successful awareness campaign it is important to take the following into consideration:

o The government should assign a responsible body, and provide them with a budget for their work.

o The assigned body should_establish a partnership with media parties and relevant entities, that can help facilitate their work and set up a strategy for this campaign.

o Identify the goals and the objectives of the campaign in advance and monitored and followed upon along the process.

o Identify the tools required for the campaign and target them (i.e. television, radio, seminars, workshops, etc.)

0 Conduct proper research to identify the target groups and the level of existing knowledge in the matter.

o Public participation and communication is very important for engaging audience and increase their awareness.

o The responsible party should monitor, evaluate and update the campaign.

o The advertising campaigns should involve different genders and age groups in order to increase the required impact.

o A marketing campaign should involve a long term plan in order to effectively harvest its efforts and prevent it from fading away.

o The responsibly body should collaborate and partnership with more entities on the long term to insure the exchange of the acquired knowledge across different sectors.

2) Case Study 2

A very similar case of the Egyptian electricity crisis happened in California in summer 2001. Pacific Gas and Electric (PG\&E), California's largest electricity provider experienced its highest peak to date [23]. This energy crisis along with 
the extensive media coverage it received, along with the economic downturn caused much more impact than the 1970's energy crisis.

In the first few months of this crisis the general public blamed the politicians and governmental institutes as the responsible parties for what took place. This is also strongly related to the Egyptian case, where people focused only on the problem from the supply side; blame the government in a time of severe political instabilities causing a huge burden and on any government and no satisfaction from the general public side.

The Californian crisis has led policymakers to adopt a PIC that they called "Flex Your Power" as a tool that can help encourage the public to take energy saving measures. In the beginning the focus was on the supply side, trying to find different options for energy supply like diesel and nuclear power plants. However, the government then started to realize that emergency conservation could be the only viable solution to deal with the problem on the short term. In January 2001 the Governor signed a legalization to implement aggressive conservation actions. The governor assigned one of California's major advertising agencies called "Grey Worldwide" as the design team for the campaign, on February 2001 the "Flex Your Power" media campaign was launched state-wide [25].

The campaign has categorized their target according to different age and ethnic groups and language spoken. The age group selected was adults between 25 47 years old as primary their target, and teen-ager age 12-17 and their secondary one.

Different ads were designed for different ethnic groups, and popular sports were also used to promote for the campaign. The designed ads were simple and designed as public announcement and not a commercial message.

Due to the charged political atmosphere, and in order to avoid the blame policy directed to the government the campaign was only associated with the Department of Consumer Affair, which was intended to remove the campaign form the blame directed toward the government.

The messages used in the campaign illustrated simple methods that end-users can use, instead of focusing on illustrating the cost effectiveness of these methods. To make the promotional message more tangible the campaigns used images that can help viewers visualize using energy. Repeated exposure and airing of the ads over an extended time increases the possibility that consumers will understand the message [23].

"Flex Your Power" presented consumers with the idea that the time of the day that electricity will be used matters too. The campaign also considered social norms and social responsibilities in the form of highlighting what people expect from others. The campaign allowed people to voice out their solutions and participate in solving the problem. This factor played a very important role in the campaign success [25].

"Flex Your Power" derived its messages from the theory of planned behaviour [23]. Many researches argued and illustrated the role of the planned behaviour as an important factor to create a successful campaign. In the research by Al- 
berta Bandura, she stated that a message that says "I can do it" is more effective in achieving energy efficiency than illustrating cost savings [26]. The campaign also used models and behavioural modelling, where well known comedians were associated in order to deliver the required message to the public.

As a result of the campaign and over the course of 2001 Californians reduced their peak demand by $8.9 \%$ and their energy consumption by $6.7 \%$ [23]."Flex Your Power" campaign has illustrated the role that a well-structured campaign can demonstrate and that awareness campaign can be a short term policy solution.

\section{Lessons learned:}

This case presents many points of similarities to the Egyptian power crisis, which are illustrated in Table 3.

On the other hand, there are many lessons that can be drawn from this case that can also be very useful for Egypt and they are deduced as following:

o Awareness campaigns represent a short term viable solution for energy related crisis.

o In order to avoid the blame policy which is happening nowadays in Egypt, the government should delegate the campaign to a governmental body that associate with the consumer rather than relate to the government, or partner with another non-governmental entity that can carry out the campaign as an separate initiative that is sponsored by the government but is done for benefiting the public.

o In order for any campaign to become successful a clear message must be delivered with simple instructions and help the audience recognise their skills and understand their capabilities of change.

Table 3. Comparison between the California Case Study and the Current Egyptian power crisis.

\begin{tabular}{|c|c|c|c|}
\hline \multirow{5}{*}{ 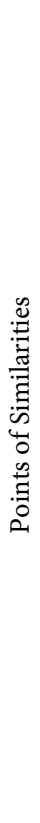 } & & 2001 California Power Crisis & Current Egyptian Power Crisis \\
\hline & 1 & $\begin{array}{c}\text { One of the worst power crisis that faced } \\
\text { California and the United } \\
\text { States in general. }\end{array}$ & $\begin{array}{l}\text { One of the worst energy crisis that } \\
\text { has faced Egypt especially in a } \\
\text { time of political change } \\
\text { and instability. }\end{array}$ \\
\hline & 2 & $\begin{array}{l}\text { People were very much aware of the } \\
\text { problem and it became their focus } \\
\text { due the actions that they face } \\
\text { on their daily life basis. }\end{array}$ & $\begin{array}{l}\text { People are aware of the problem } \\
\text { as they face its consequences } \\
\text { on daily basis. }\end{array}$ \\
\hline & 3 & $\begin{array}{l}\text { People blamed the government } \\
\text { and the political atmosphere } \\
\text { became very charged. }\end{array}$ & $\begin{array}{l}\text { People blamed the government, } \\
\text { which made the political } \\
\text { atmosphere very unstable. }\end{array}$ \\
\hline & 4 & $\begin{array}{l}\text { On the first impulse the government's } \\
\text { proposed solutions were focused on the } \\
\text { supply side and finding alternatives like } \\
\text { diesel and nuclear power plants. } \\
\text { However, state official realized that } \\
\text { emergency conservation means } \\
\text { represent a viable short term solution. }\end{array}$ & $\begin{array}{l}\text { The government's proposed } \\
\text { solutions are focused on the } \\
\text { supply side with very limited } \\
\text { focus on the demand side. }\end{array}$ \\
\hline
\end{tabular}


o Nothing should be mass about an awareness campaign.

o The message of the campaign should target the right audience, where audience are analysed, separated into different groups (i.e. age, gender, educational level, etc.) and separately attract the attention of each.

o The campaign should provide the audience with information about the desired action and the skill to do it.

o Open a channel of communication to allow people to participate, engage and share their own solutions for the problem.

o Theories of planned behaviour argues that depending on motivation methods that help people understand and realise they have an impact to solve the problem, rather than providing a cost benefit info which is usually the hallmark of most energy conservation campaigns could be more effective in this case.

o Persistence and constant reminder is very critical to assure the long term success of the campaign.

o Reward policy and reinforcement is required in association with any energy conservation campaign, in order to guarantee the new requested behaviour becomes a habit.

\subsubsection{Motivation}

Due to different structural barriers, end-users are usually prevented from benefiting of opportunities presented by different efficiency options [7]. This is usually due to the lack of incentives that can push towards the implementation or the actual use of different efficiency measures. It could also be due to resources barrier including lack of technology or the required fund that can help end users to consider energy efficiency options.

It is also important to note that studies have showed that when it comes to motivating users to consider energy efficiency applications, there are two equally important aspects concerned. The two aspects are hedonic or cost reasons, and normative reasons or environmental reasons. Studies illustrates that the normative or the environmental reasons are very important to promote energy efficiency [15] [27]. These studies assume that those normative reasons are more robust against change [1]. However, the normative concerns usually require longer time of implementation, and awareness, which becomes a problem in the Egyptian case due to the general lack of awareness, and due to the sensitive case of the current power crisis which requires more prompt actions in order to provide a quick solution. Yet there is an adequate logic in presuming that any long term strategy should also focus on those normative concerns as a valid aspect of the problem, however within the scope of this study the focus will mainly be on hedonic, cost reasons and the lack of resources concerns.

In order to successfully promote energy efficiency; there is a need to acquire some form of investment in new technology, equipment or processes. Campaigns that advocate investments in energy efficiency may need to be accompanied by financial incentives in order to be successful [11]. Many developed countries have started allocating a specific fund and resources that can help back 
up and motivate users to consider energy efficiency techniques. The ultimate goal of these strategies is to assure that the energy efficiency finance become an ordinary part of the lending process, and specifically with banking involved [28].

In order to reflect on the financing aspect which plays a major role in the motivation process, and its allocation could somehow properly guarantee the promotion of energy efficiency, the research will be looking into a few case studies to reflect on their stories of success, and highlight the main lessons learned.

Case study 1

In June 2010 it was reported [28], that the state of Philadelphia, USA, has initiated a new model of financing energy retrofitting commercial existing buildings or new built ones. Although this example is mainly tackling commercial buildings however the lessons learned are related to different sectors and can be adapted for use across the residential sector as well.

The initiative was called the Green-works Loan Fund, and its aim was to make energy efficiency financing an ordinary part of the lending process. The funding scheme was capitalized through a combination of federal fund and private funding. The funded proposal had to aim to at least reduce $25 \%$ of its energy use.

The Green-works Loan fund was a complimentary scheme aimed for commercial buildings but complementing other existing schemes that were aimed for residential ones.

The loaning scheme was the work of collaboration between three different partners along with an executive power represented by the deputy mayor for planning and economic development acting as the lead. The main capital for the fund came from the Philadelphia Industrial development Corporation (PIDC), which is a private non-profit corporation formed by the city to promote economic development. The second partner was The Reinvestment Fund (TRF), which was a community development financial institution. Also independent professional engineers were used to audit the offered proposals.

The scheme was successful in addressing a diverse mix of projects and was able to open several rounds for applications.

There were different challenges that faced these funding schemes and it is important to highlight them in order to properly reflect on them within the lessons learned, and they are summarised as following:

- Attracting developers that are sufficiently informed on energy efficiency and its difference means.

- Allocating private sector finance and attracting the interest of banks as a financing mechanism.

- Value engineering and the evidence and data backing any proposal up, is usually project specific and varies from one proposal to another, so that the process of selection needed more time and careful technical attention, so as to insure the required results of energy savings.

Lessons Learned

o Awareness and on energy efficiency tools and consideration is a very important aspect in attracting the right workable proposals. 
o Partnership becomes and important element to facilitate the financing mechanism and allocating the right experience that can help monitor and assure the quality of the work from start to end.

o It is very important to utilize existing expertise and insure that the funding mechanism has its own special authorization to eliminate the additional time of implementation.

o Public-private partnership helps facilitate the financing mechanism, relieve the government from budget overload, and assure that the financial resources are scaled up on the long run.

o Creating loans that are use standard lending process which is already a typical part of financing different new projects and the procedures are clear for the interested parties.

o Contracting professional engineers to audit the work is an important guarantee for the effectiveness of the proposed projects and an assurance to successful results.

o Continuous monitoring and auditing to the proposed projects is very important to effectively achieve the required energy savings.

o Attracting private investment is a core element that guarantees the survival of similar funding schemes. Also it is very important to make this lending process very transparent and well monitored in order, to assure quality and attract the interest of private financing.

o Banks becomes a very important player in relation to the previous point and the government has to assure that the risks of these energy loans are very low for the participating banks.

\section{Other Case studies}

In June 2011, it was reported [29], that in Saint Louis county, USA, the local government as a result of the Energy Improvement and Extension act of 2008, were able to borrow money to fund Qualified energy conservation projects based on a debt instrument called the Qualified Energy Conservation Bond (QECB). The QECB had an interest below a $2 \%$, which was very encouraging to home owners in term of considering energy efficiency applications in their buildings.

Another example for this was a case presented in Lithuania where renovation programs allocated there were based on state grants and commercial bank loans [30]. However, with the economic crisis this model was not very successful and it was discouraging for home owners to use. In return the source of financing was allocated to a $3 \%$ combination of 3\% from EU structural funds, a 15\% from a state grant, and $25 \%$ from a climate change program which took the burden from the state budget.

In another case from Lithuania and in order to encourage low income home owners to actively seek energy efficiency, it was provisioned that in case of renovation the owners should get a subsidy covering $100 \%$ of the renovation costs. However even with this legal act, the participant numbers were still low, so on May 2013 it was announced that the law on social assistance for poor families and single residents was amended that any home owner who fails to participate 
in the renovation may lose from $50 \%$ to $100 \%$ of their energy costs subsides for a period of three years [30]. This law enforcement was a successful step in promoting energy efficiency, which brings us to the next discussed point under the compliance part.

\section{Lessons learned}

o It becomes very beneficial that the government organize and facilitate energy conservation bonds, especially those with low rate of interest of no more than $105-3 \%$. This in return will encourage homeowners to consider energy efficiency improvements to their homes through this flexible loaning mechanism.

o Allocating different combined funding schemes in order to provide less pressure on the government.

o Law enforcement is very important to run along with motivational schemes in order to guarantee the required implementation; this will be discussed within the following point.

\subsubsection{Compliance}

Along with public awareness campaigns and motivational schemes there should be law enforcements and regulations that can help push toward the required behavioural change. This is particularly related to conservation methods in developing countries, where sustainability and energy efficiency is not well implemented or even considered by the society.

When seat belts were invented to be used in cars, the public were not well aware of their benefits and usefulness, and they were reluctant to use them. However, in during the 60s and the 70s governments started to introduce fines and penalties to enforce their use. This has had a very positive effect on their spread of use. So now they are widely used especially in developed countries and people are highly aware of their importance [11].

In Egypt, "Our problem is enforcement. I would say $60 \%-70 \%$ of environmental regulations is not enforced. I think enforcement is the first step to reform the system." "There isn't enough awareness about the importance of enforcing environmental regulations, and the impact of implementing them is not clear to the public. By enforcing the laws, we do not mean just punishing violations, but also providing incentives." says Dr. Al Haggar [31].

One of the main problems facing the enforcement issues in Egypt is the conflict of interest and the fact that there is too many parties involved (mention the names of the entities), so that the rules of regulations are not properly enforced, updated or followed through. Hence there is an important need to assign a specific responsible body that can formulate, regulate, monitor, and update the required law that can help to properly implement energy standards and increase the required efficiency of the residential sector.

1) Energy Standards in Egypt

"The energy standard for housing in Egypt became law in 2005. The standard has both prescriptive and performance-based compliance paths. It also includes minimum performance levels for air-conditioners and other appli- 
ances application" [32]. The energy code is designed to cover all housing types and it tackles some requirements for electrical lighting and equipment as shown in Figure 7.

On the other hand, it was noted that the residential buildings energy efficiency code (RBEEC) is far from being integrated into the construction industry in Egypt due to two main reasons:

a) The lack of public and professional awareness towards the topic of energy efficiency;

b) The absence of incentive laws and regulations to apply it [9].

It is very important to account these two factors into any solution proposed to deal with the energy problem in Egypt, as with abiding with this code there will be unrequired energy loss that could be avoided otherwise and can result in the reduction of energy used and the cost induced accordingly, and hence provide savings on the smaller scale like; users and tenants level, and reaching all the way to the bigger scale on the national level.

Hence it is important to structure the required laws and regulation, that are well designed to promote energy efficiency to users and that has an obvious impact if they are not properly followed or implemented.

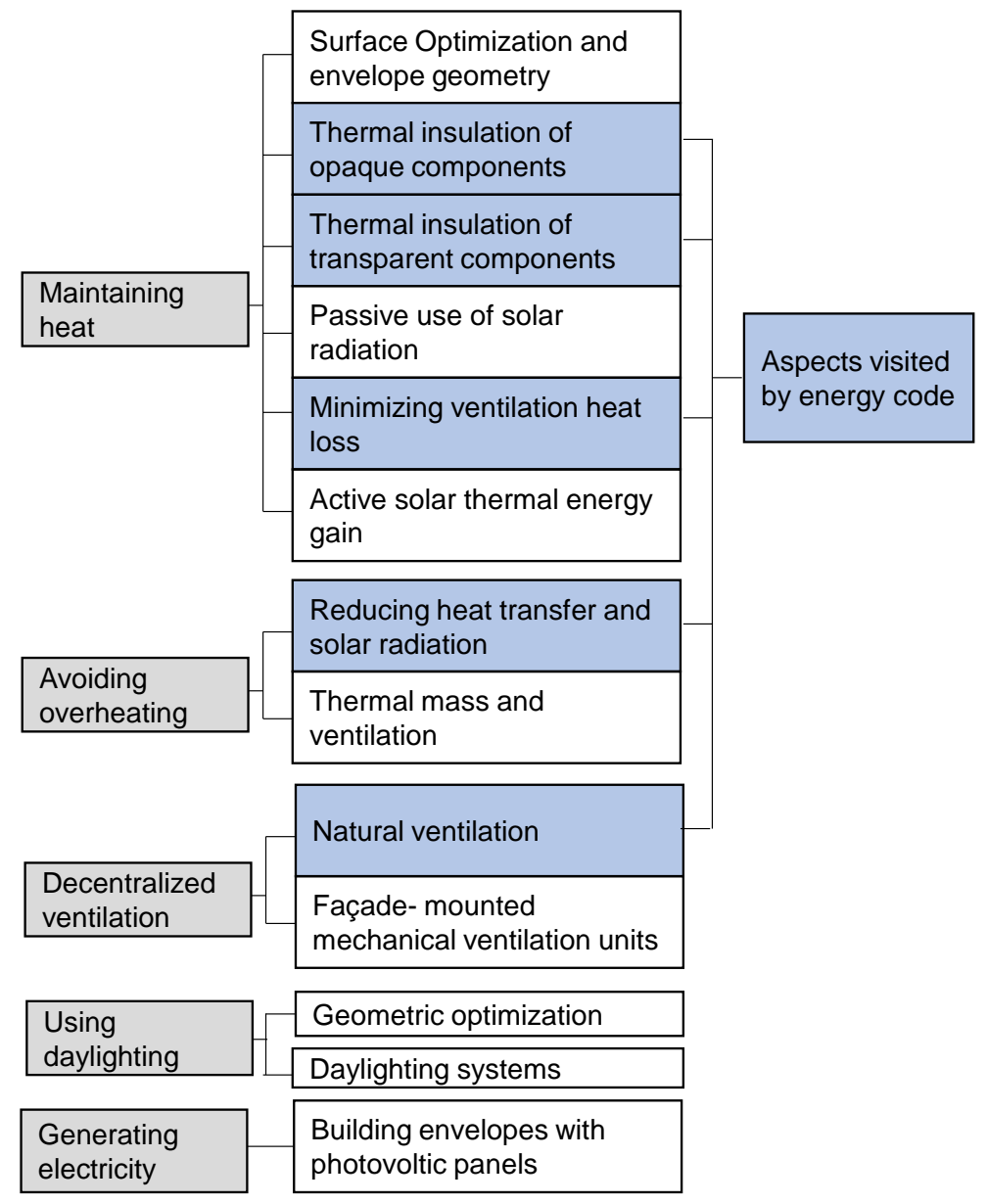

Figure 7. The aspects integrated in the structure of residential building's energy efficiency code [33]. 


\section{Conclusions}

Egypt is in a good position to look into the proper use of solar and wind energy in its energy supply proposed agenda. It also has available technical and management skills that can be altered and invested in the required associated technologies. However, in order to properly formulate these technologies, they should propose and allocate a clear vision and the appropriate organizational arrangement that can help induce renewables in the supply side's agenda [2].

In Egypt nowadays it is important to raise awareness towards energy efficiency from the demand side. The current power crisis has caused the general public to relate to the problems, and understand the need to solve it, while facing challenges that such problem is inducing on their daily life. This is a very good time for the government to start an awareness campaign while all attention is drawn to the current situation.

Another point is the high increase in the utility bills that the government has started to apply nowadays, where it is safe to say that end-user's attention is now drawn towards finding solutions to the energy problems, and is willing to try them out, and find alternative to decrease their energy consumption and save on their energy bills.

On the other hand, it is important to note that energy efficiency has always been a hard sell as electricity is invisible [18], and most probably it represents an intangible problem and solutions. So that to properly tackle energy efficiency it is important to plan a multi-faceted sets of interlocking strategies that evolve over time along, and try to target end-user's behaviours as a way to achieve the policy's goals on the long run [23].

In term of awareness it is generally deduced that the lack of an access to upfront proper capital can direct an end-user away from many energy efficiency methods that could save them energy and money on the long run [7].

Nevertheless, finance and setting a budget for these campaigns and for other energy efficiency schemes will remain an issue that will remain to face the government, and hinder the compliance of the end-users in considering efficiency measures. In return an allocated budget or a set financial scheme should be well investigated in order to identify the required financial arrangements to push for the required efficiency. This will be quickly reviewed within the next part as part of the challenges of the power crisis, but in this research it will not be the main focus of discussion.

When it comes to awareness campaigns it is important to define a target audience, select relevant information channels to reach the target and capture the required attention [22].

In general, public awareness campaigns should not only focus on alerting the users to the economic savings that they will gain from any energy efficiency measures applied, but they should also highlight the environmental benefits they can gain and the negative impact that is associated to the current growing energy use. Hence public awareness campaigns are designed to reflect the bigger picture and the quality of life that energy efficiency measures will offer the users on the 
long run [11].

\section{Recommendation \&Proposed Solutions}

In order to properly purse energy efficiency on the national level the Egyptian government should set a long term strategy that should fulfil and include the following:

- Energy efficiency must be considered as an important resource of any proposal to approach the energy problem. So that it has to be included within both the supply and the demand strategies that are proposed to deal with the energy problem both on the short term and on the long run.

- There should be a continuous improvement for the policy and regulations that are pushing for achieving energy efficiency, in order to properly formulate the required strategy, and make it a part of the legal constitutional force.

- On the national level, it is very important to formulate an integrated framework that is based on best case examples in order to unlock the full potential of any energy efficiency schemes.

- Allocate upfront funding that can help support and maintain any planned scheme for energy efficiency. This has to be done through a tailored financial mechanism that cans interest different parties in the application of energy efficiency in order to remove some of the burden from the government and generate a market niche for energy efficiency in different sector.

- Guarantee and maintain alignment between different parties and stake holders involved in any energy efficiency scheme.

- Prepare a long term plan in any strategy that is designed to promote energy efficiency in order to adequately apply and maintain its outcome for a long time.

- Innovation and development should be well integrated and though of for inclusion on the long term of any energy efficiency scheme in order to guarantee its workability on the long term.

- The government has to continuously work on the reforming and monitoring of the energy prices in order to sustain its economy and control the demand side, however this should be done in a balanced convenient way without overburdening the users and it should happen based on continuous investigation to the market status in order to guarantee fairness for all sides.

- The government has to continuously work on reforming and monitoring the institutional structure that is used to promote energy efficiency schemes and different related activities.

- Analyse and evaluate any market failure, in order to formulate lessons that can help prevent its reoccurrence.

- Establish partnership that can help in promoting and developing energy efficiency in the market.

- Set priorities, hierarchy for introducing energy efficiency where it is mostly needed first.

Finally, the Table 4 deduce the overall lessons learned and actions 
Table 4. Main actions needed to promote energy efficiency.

\section{Awareness}

In order to promote energy efficiency and implement its awareness the following aspects should be taken into consideration.

- It require a political interventional and a long term commitment by the government.

- To avoid the blame policy the government should delegate the responsibility to a specialized governmental body that is rather related to the consumer.

- The government should develop a comprehensive information and data system that is transparent for the users and available for as reference to different stakeholders.

Policy

- An intervention plan has to be taken into consideration in order to properly formulate the required policy.

- The assigned body should be responsible and dedicated to the energy efficiency awareness plan, and it has to have the required legal and executive powers to push for the required changes.

- The assigned body has to incessantly follow up on the steps taken, monitor, evaluate and continuously support the plan in order to guarantee a long term commitment and an effective result.

- The governmental body should identify and structure a clear goal, time span and statement for the required adopted policy plan.

- The government body should utilise different tools like media and others to insure effective communication with the public.

- The government or the assigned responsible party should set up a partnership with different entities that can help to promote and deliver the required plan for implementing energy efficiency.

- The partnership should involve professionals that have the right experience to formulate the required plan, this could include media partners, marketing partners and others relevant parties.

Partnership - The partners involved should conduct proper market research that will allow guiding for the best tools to approach the public.

- There should be an on-going cooperation with other sectors like industry and manufacturing.

- There should be an interval consultation with the industrial sector every few years.

- Financial and physical resources should be mobilized to support the required actions.

- A dedicated fund should be allocated to support the promotion plan.

- There is a need to have interval inspection to the funding scheme in order to maintain and monitor its allocation towards the right path.

- Users should be approached not as amass but should be divided into different sectors of age, status and even gender as possible.

End-Users - The public must be well included and well informed throughout the process.

- Transparency and clarity is a key factor to guarantee that the public not only understand but is also involved in the decision making process.

- End-users must be given clear options that can help them achieve energy efficiency.

- The time plan for the awareness scheme should allow a long term commitment and proper follow up in order to monitor up date and include new emerging technologies.

Time Plan

- A regular follow up with a short time span should be taken into consideration to assure that all the required are properly applied and followed through.

\section{Motivation}

- It is important to relate obvious and quick wins for all players.

- Including a reward policy in the structured plan in order to encourage different users and even investors to take charge.

- Allocate funds from different sources and stimulate the private sector to invest in order to decrease the financial burden on the government.

- Use structured funding schemes that involve low interest return, and low risks to encourage investors.

- Include banks, NGOs and other players that can help stimulate and properly run the promotional schemes.

- Include and insure attracting the interest of the industry and private investors to take part in EE initiatives.

- Establish public-private partnerships.

- Banks becomes a very important player and attracting them is vital to guarantee the allocations of the required funds.

- Partnering with NGO's and interties like development banks in order to facilitate financial allocation and

experts involvement.

- Including Experts that can help audit, monitor and develop the efficiency schemes. 
required for energy efficiency implementation, based on the three main points of discussion: awareness, motivation and compliance.

\section{References}

[1] International Energy Agency (2011) World Energy Outlook. OECD, France. https://doi.org/10.1787/weo-2011-en

[2] Razavi, H. (2012) Clean Energy Development in Egypt. African Development Bank. African Development Bank (AfDB) Group, Tunisia.

[3] World Bank (2010) Egypt: Improve Energy Efficiency. Sustainable Development Department (MNSSD) Middle East and North Africa Region, Egypt.

[4] Ministry of Electricity \& Energy New \& Renewable EnergyAuthority (NREA) (2011) Annual Report 2011. Ministry of Electricity \& Energy New \& Renewable Energy Authority, Cairo.

[5] Egyptian Electricity Holding Company (2012) Annual Report 2011, 2012. Egyptian Electricity Holding Company, Cairo. http://www.moee.gov.eg/english_new/EEHC_Rep/2011-2012.pdf 
[6] Clough, R. (2015, March 13). Bloomberg. Retrieved from News: http://www.bloomberg.com/news/articles/2015-03-13/ge-sells-1-billion-of-turbinesin-10-boost-to-egypt-power-grid

[7] Granade, H.C. (2009) Unlocking Energy Efficiency in U.S. Economy. McKinzy \& Company, USA.

[8] Fisk, W.J. (2002) How IEZ Affect Health Productivity, Ashare.

[9] Ahmed Nabih Ahmed, M.M. (2011) Using Simulation Tools for Enhancing Resedentail Buildings Energy Code in Egypt. Proceedings of Building Simulation 2011: 12 th Conference of International Building Performance Simulation Association (IBPSA), Sydney, 14-16 November 2011, 1141-1148..

[10] Akker, J.V. (2010) Energy Efficiency Improvement and Greenhouse Gas Reduction project. United Nation Development Program, Egypt.

[11] Kim, K.-H. (2007) Overview on Public Benefit Campaigns to Promote Energy Conservation and Energy Efficiency. The United Nations Forum on Energy Efficiency and Energy Security: Taking Collaborative Action on Mitigation Climate Change. United Nations, Seoul.

[12] Ryan, N. and Thomas W. (2008) Top-down organizational change in an Australian Government agency. International Journal of Public Sector Management, 21, pages.

[13] International Organization of Supreme Audit Institutions Working Group on Environmental Auditing (2010) 2011-2013 Work Plan. INTOSAI, South Africa.

[14] Vaughan, S. (2014) Converging Opportunities: Environmental Compliance and Citizen Science. International Institute for Sustainable Development, USA.

[15] Steg, L. (2008) Promoting Household Energy Conservation. Energy policy 36.

[16] Sunikka, M.M. (2006) Policies for Improving Energy Efficiency in the European Housing Stock. ISBAN 1-58603-649-1.

[17] Thompson, J. (2015) Dar Al Hekma Workshop. Jeddah.

[18] Gardner, L.A. (1992) Consumer Processing of Social Ideas Advertising: A Conceptual Model. Advances in Consumer Research, 19, 15-22.

[19] Bord, R.J. and O'Connor, R.E. (2000) In What Sense Does the Public Need to Understand Global Climate Change? Public Understanding of Science, 9, 205-218.

[20] Baird, J.C. and Brier, J.M. (1981) Perceptual Awareness of Energy Requirements of Familiar Objects. Journal of Applied Psychology, 66, 265-276. https://doi.org/10.1037/0021-9010.66.1.90

[21] Andersen, R.M. (1995) Revisiting the Behavioral Model and Access to Medical Care: Does It Matter? Journal of Health and social Behavior, 36, 1-10. https://doi.org/10.2307/2137284

[22] Weiss. J.A. and Tschirhart, M. (1994) Public Information Campaign as Policy Instruments. Journal of Policy Analysis and Management, 13, 82-119. https://doi.org/10.2307/3325092

[23] Sylvia, L. and Bender, M.M. (2001) Using Mass Media to Influence Energy Consumption Behavior: California's 2001 Flex Your Power Campaign as a Case Study. Human and Social Dimensions of Energy Use: Understanding Markets and Demand.

[24] Valuntiené, I. (2009) Contextualising Behavioural Change in Energy Programmes Involving Intermediaries and Policymaking Organizations Working towards Changing Behaviour. Cowi Baltic. European commission, Lithuania.

[25] California Department of Consumer Affair (2001) Flex your Power: Product Image Case Study. California Department of Consumer Affair, Energy Conservation Ini- 
tiative, California.

[26] Bandura, A. (1997). Self-Efficacy: The Excercise of Control. W.H. Freeman and Company, New York.

[27] Lindenberg, S. and Steg, L. (2007) Normative, Gain And Hedonic Goal-Frames Guiding Environmental Behavior. Journal of Social Issues, 63, 117-137. https://doi.org/10.1111/j.1540-4560.2007.00499.x

[28] Institute for Sustainable Communities in partnership with Living Cities (2010): Climate Leadership Academy (CLA), Philadelphia.

[29] Environmental Energy Technology Division (2011) Using Qualified Energy Conservation Bonds (QECBs) to Fund a Residential Energy Efficiency Loan Program: Case Study on Saint Louis County, MO. Lawrence Berkley National Laboratory, Environmental Energy Technologies Division, Saint Louis.

[30] Baltic Surveys/Gallup (1999) Final Report of Energy Efficiency. Vilnius.

[31] Masry, S.A. (2016) Egypt: The Question of the Environment. Daily News, Cairo, Egypt.

[32] Royal Institute of Chartered surveyors (2009) Can Building Code Deliver Energy Efficiency.

[33] Hegger, M. and Matthias, F. (2008) Energy Maual. Sustainable Architecture, Basel, Boston, Berlin.

Submit or recommend next manuscript to SCIRP and we will provide best service for you:

Accepting pre-submission inquiries through Email, Facebook, LinkedIn, Twitter, etc. A wide selection of journals (inclusive of 9 subjects, more than 200 journals)

Providing 24-hour high-quality service

User-friendly online submission system

Fair and swift peer-review system

Efficient typesetting and proofreading procedure

Display of the result of downloads and visits, as well as the number of cited articles

Maximum dissemination of your research work

Submit your manuscript at: http://papersubmission.scirp.org/

Or contact epe@scirp.org 